\title{
Occurrence of pathogenic environmental mycobacteria on surfaces in health institutions
}

This article was published in the following Dove Press journal:

Research and Reports in Tropical Medicine

15 October 2010

Number of times this article has been viewed

\author{
Maria Gorete Mendes \\ dé Souza' \\ Daisy Nakamura Sato² \\ Clarice Queico Fujimura \\ Leite $^{3}$ \\ Sérgio Roberto de Andrade \\ Leite $^{4}$ \\ Flávio Garcia Sartori' \\ Karina de Andrade Prince ${ }^{3}$ \\ Luciana Assirati Casmeiro' \\ Carlos Henrique Gomes \\ Martins ${ }^{\prime}$ \\ 'Laboratório de Pesquisa em \\ Microbiologia Aplicada, Universidade \\ de Franca, Franca, Brazil; '2Laboratório \\ de Micobactéria, Instituto Adolfo Lutz, \\ Ribeirão Preto, Brazil; ${ }^{3}$ Departamento \\ de Ciências Biológicas, Universidade \\ Estadual Paulista, Araraquara, Brazil; \\ ${ }^{4}$ Instituto de Química, Universidade \\ Estadual Paulista, Araraquara, Brazil
}

Correspondence: Carlos Henrique Gomes Martins

Ave Dr Armando Salles Oliveira, 20I,

Franca I4404-600, São Paulo, Brazil

Tel +55 I6 37।I 8756

Email martinsc@unifran.br
Abstract: The presence of environmental mycobacteria on surfaces in two public health institutions, namely a health center and a hospital in upstate São Paulo (Brazil), was identified by polymerase chain reaction-restriction enzyme analysis (PRA). The possible sources of contamination by these microorganisms were evaluated, contributing to epidemiology studies.

Methods: From June 2005 to June 2006, a total of 632 samples were collected from exposed surfaces, such as washbasins, drinking fountains, and other accessible sites, and the mycobacteria present in the samples were isolated and cultured.

Results: Sixty-five mycobacteria were isolated from the 632 samples; 47 of which were detected in samples from the health center and 18 in samples collected from the hospital. The isolates were identified by DNA restriction patterns obtained by PRA, and potentially pathogenic species were found to be prevalent among the identified mycobacteria. This study shows that the PRA technique can be employed as a fast and easy method for identification of nontuberculous mycobacteria in public areas.

Conclusions: The isolation of environmental mycobacteria from the two health institutions demonstrates that these surfaces are reservoirs of potentially pathogenic mycobacteria and indicates the need for continuous maintenance and monitoring. These data will add to the study of the epidemiology of these microorganisms.

Keywords: environmental mycobacteria, health center, PCR, PRA

\section{Introduction}

Mycobacteria that do not belong to the tuberculosis (TB) complex (Mycobacterium tuberculosis, M.bovis, M. africanum, and M.microti $)^{1}$ or cause Hansen disease (M. leprae) are known as nontuberculous mycobacteria (NTM). ${ }^{2,3}$

Currently, over 120 species of mycobacteria are recognized. ${ }^{4}$ These mycobacteria are remarkably resistant to low levels of nutrients, being persistent even in running water. ${ }^{5}$ They also tolerate extreme temperatures and are usually resistant to disinfectants. They can contaminate medical equipment, such as bronchoscope washers or samples in the laboratory, consequently causing pseudo-infections. ${ }^{6,7}$ NTM may infect human beings either by ingestion or inhalation and have a twofold effect. ${ }^{8}$

The potentially pathogenic species can be the cause of a variety of diseases in humans and animals, differentiated by the severity of symptoms and importance in terms of public health. ${ }^{9}$ Person-to-person transmission does not occur, and it appears that environmental exposure plays an important role in human infections with NTM. ${ }^{10}$ 
Identification on the basis of DNA methods, particularly the polymerase chain reaction (PCR) with restriction enzyme analysis (PRA), is a promising means for the rapid and accurate identification of mycobacterial species. ${ }^{11,12}$

The aim of the present study is to assess the incidence of NTM in public health institutions employing analysis of DNA restriction patterns by PRA, and thus, contribute to studies on the epidemiology of these organisms isolated from yet noninvestigated surfaces of hospital clinical environments. The possible sources of contamination by these microorganisms are also examined.

\section{Methods}

\section{Collecting sites}

A total of 632 samples were collected from clinical environments of two health service institutions in a city in upstate São Paulo, Brazil; 316 samples were collected at the Department of Infectious and Contagious Diseases of a public hospital, whereas 316 samples were obtained from the Lung Disease division of a health center.

There are no studies focusing on the presence of mycobacteria on the surfaces of the clinical environments of health service institutions; however, it is noteworthy that these surfaces are easily accessible and can become a source of contamination for patients who have contact with them.

In the case of the hospital, samples were taken from washbasins in the bathrooms and corridors (near the drains and faucets) in the vicinity of the wards, from flooring in the bathrooms and wards, and from toilet seats. This hospital assists patients admitted due to bacterial or viral diseases.

As for the health center, the sampling sites were drinking fountains (near the drains, around and above the operating button, and on the sides), waiting room benches, and sinks in the vaccine and dressing stockrooms (drains and faucets). This center provides clinical care, diagnosis, and treatment for patients with TB.

Further samples were collected from places where the presence of mycobacteria was suspected.

\section{Isolation of NTM}

Samples were collected in alternate months between June 2005 and June 2006 in both institutions under study. Surfaces at the locations detailed above were wiped with sterile, damp swabs, which were then tested on site by the method of Kudoh and Kudoh. ${ }^{13}$ After being soaked for 2 minutes in $4 \% \mathrm{NaOH}$, to reduce the growth of other microorganisms, the swabs were rubbed over the surface of slants of Ogawa medium. ${ }^{13}$ The tubes were incubated at $25^{\circ} \mathrm{C}$ and $37^{\circ} \mathrm{C}$ for 60 days and observed daily. The growth rate, morphology, and pigmentation of each of the isolated mycobacterial colonies were noted.

\section{DNA extraction, PCR, and restriction enzyme analysis}

The molecular methods used in the DNA analysis were taken from the work of Rocha et al. ${ }^{14}$ The results were interpreted by comparing the fragment profiles with standard PRA tables, which can be accessed at http://app.chuv.ch/prasite/ index.html.

\section{Results}

Out of the 632 samples collected from the two institutions over a 13-month period, being 316 samples collected from each institution, 65 (10.3\%) yielded viable mycobacteria, 131 $(20.7 \%)$ were contaminated by other microorganisms, and $436(69.0 \%)$ did not produce any microbial growth.

A comparison of the prevalence of NTM in the two institutions investigated in this study shows that the number of positive samples (Table 1) in the hospital was lower $(18 \% / 27.7 \%)$ than in the health center $(47 \% / 72.3 \%)$.

The PRA results identified 62 of the mycobacterial isolates to the species level (Table 1). In three isolates, the results were inconclusive, because their restriction patterns are as yet unknown and are not listed in the PRASITE databank published in 2006.

The species identified by PRA in this study demonstrated a slight prevalence of potentially pathogenic mycobacteria, which formed $53.2 \%$ of the total of 62 isolates, whereas the remaining $46.8 \%$ were rarely pathogenic species. Furthermore, the majority of potentially pathogenic species were found in the health center.

Among the investigated locations, the drinking fountain localized at the health center presented the largest incidence of mycobacteria: 35 isolates, which corresponds to $56.4 \%$ of the total number of isolated species (62). The main species encountered in this place were $M$. gordonae type 3, M. kansasii type 4, M. malmoense type 1, and M. simiae type 4.

Surprisingly, the most pathogenic species detected in the present work, such as $M$. avium type 2 and $M$. fortuitum type 1 , were isolated from the bench in the waiting room of the health center.

In the hospital wards, the most prevalent species were $M$. gordonae types 1 and 3 and $M$. malmoense type 1, which 
Table I Description of the 62 isolates identified by PRA showing the number of a given species isolated at each collection point and the respective pathogenicity class

\begin{tabular}{|c|c|c|c|c|c|}
\hline Location of sample collection & Isolates $(n=62)$ & Species & Type & Institution & Pathogenicity \\
\hline \multirow[t]{2}{*}{ Waiting room bench } & 1 & M. avium & 2 & $\mathrm{C}$ & PP \\
\hline & 1 & M. fortuitum & I & C & PP \\
\hline Total isolates & 2 & - & - & - & - \\
\hline \multirow[t]{3}{*}{ Drain in bathroom } & 1 & M. flavescens & I & $\mathrm{H}$ & $\mathrm{RP}$ \\
\hline & 1 & M. gordonae & 1 & $\mathrm{H}$ & $\mathrm{RP}$ \\
\hline & 1 & M. new type & 1 & $\mathrm{H}$ & $\mathrm{RP}$ \\
\hline Total isolates & 3 & - & - & - & - \\
\hline \multirow{3}{*}{ Toilet seat } & 2 & M. fortuitum & 1 & $\mathrm{H}$ & PP \\
\hline & 1 & M. gordonae & 1 & $\mathrm{H}$ & $\mathrm{RP}$ \\
\hline & I & M. vaccae & 1 & $\mathrm{H}$ & $\mathrm{RP}$ \\
\hline Total isolates & 4 & - & - & - & - \\
\hline \multirow[t]{9}{*}{ Drinking fountain } & 1 & M. gastri & I & C & $\mathrm{RP}$ \\
\hline & 1 & M. genavense & 1 & C & PP \\
\hline & 1 & M. gordonae & 1 & C & $\mathrm{RP}$ \\
\hline & 9 & M. gordonae & 3 & C & $\mathrm{RP}$ \\
\hline & 1 & M. gordonae & 9 & C & $\mathrm{RP}$ \\
\hline & 12 & M. kansasii & 4 & C & PP \\
\hline & $\mathrm{I}$ & M. lentiflavum & 3 & C & PP \\
\hline & 4 & M. malmoense & 1 & C & PP \\
\hline & 5 & M. simiae & 4 & C & PP \\
\hline Total isolates & 35 & - & - & - & - \\
\hline \multirow[t]{2}{*}{ Ward floor } & 2 & M. gordonae & I & $\mathrm{H}$ & $\mathrm{RP}$ \\
\hline & 1 & M. gordonae & 3 & $\mathrm{H}$ & $\mathrm{RP}$ \\
\hline Total isolates & 3 & - & - & - & - \\
\hline \multirow[t]{3}{*}{ Bathroom floor } & 1 & M. gordonae & 1 & $\mathrm{H}$ & $\mathrm{RP}$ \\
\hline & I & M. gordonae & 3 & $\mathrm{H}$ & $\mathrm{RP}$ \\
\hline & 2 & M. malmoense & I & $\mathrm{H}$ & $\mathrm{PP}$ \\
\hline Total isolates & 4 & - & - & - & - \\
\hline Sanitary disposal room floor & 1 & M. gordonae & 3 & $\mathrm{H}$ & $\mathrm{RP}$ \\
\hline Total isolates & 1 & - & - & - & - \\
\hline \multirow[t]{4}{*}{ Drain in washbasin } & 1 & M. gordonae & 3 & C & RP \\
\hline & 2 & M. lentiflavum & 1 & $\mathrm{C}$ & PP \\
\hline & 1 & M. mucogenicum & 1 & $\mathrm{H}$ & $\mathrm{PP}$ \\
\hline & 1 & M. new type & I & C & $\mathrm{RP}$ \\
\hline Total isolates & 5 & - & - & - & - \\
\hline Bathroom faucet & 1 & M. lentiflavum & 1 & $\mathrm{C}$ & PP \\
\hline Total isolates & 1 & - & - & - & - \\
\hline Drain in bathroom & 1 & M. malmoense & 1 & $\mathrm{H}$ & PP \\
\hline Total isolates & 1 & - & - & - & - \\
\hline Toilet flush button & 1 & M. new type & I & C & $\mathrm{RP}$ \\
\hline Total isolates & 1 & - & - & - & - \\
\hline Corridor floor & 1 & M. smegmatis & 1 & C & $\mathrm{RP}$ \\
\hline Total isolates & 1 & - & - & - & - \\
\hline Washbasin faucet & 1 & M. smegmatis & 1 & C & $\mathrm{RP}$ \\
\hline Total isolates & I & - & - & - & - \\
\hline Total general & 62 & - & - & - & - \\
\hline
\end{tabular}

Abbreviations: PRA, polymerase chain reaction-restriction enzyme analysis; C, Health center; H, Hospital; PP, Potentially Pathogenic; RP, Rarely Pathogenic.

were found mainly on the floor and drains of washbasins in the bathrooms.

Of all the species isolated from the two health institutions, five species prevailed, namely $M$. gordonae type 3 (13\%/21\%), M. kansasii type $4(12 \% / 19.3 \%)$, M. malmoense type $1(7 \% / 11.3 \%), M$. gordonae type $1(6 \% / 9.7 \%)$, and M. simiae type $4(5 \% / 8 \%)$.

\section{Discussion}

According to Falkinham, ${ }^{15}$ NTM can be especially prevalent in the water encountered in hospital environments due to the type of piping. Many hospitals have galvanized (zinc-coated) pipes in the water distribution system, which favors the formation of biofilms and thus, contributes to the persistence of these organisms in the water. In the 
present study, the number of positive NTM samples was lower in the hospital $(27.7 \%)$ compared with the health center $(72.3 \%)$. This is probably because there is a larger general microbial population in the hospital, which would lead to greater competition for nutrients among the various microorganisms present in this environment and would significantly reduce the proliferation and persistence of mycobacteria. ${ }^{16}$ This hypothesis is reinforced by the higher level of microbial contamination of the samples collected in the hospital.

The PRA results enabled identification of 62 out of 65 mycobacterial isolates. The results were inconclusive for three isolates, because their restriction patterns are as yet unknown and not found in the PRASITE databank published in 2006.

When Bland et al $^{16}$ isolated 262 mycobacteria from the wild, they identified 20 distinct species, including both pathogenic and fast-growing species. Both biochemical tests and PRA were used for microorganism identification, and the authors reported that the latter method was faster and more accurate than the former, thereby being a promising novel tool for the identification of mycobacteria present in the environment. Of course, definition of a species by this method depends on the comparison of its PRA pattern with those already known and described in PRASITE. However, as the three inconclusive patterns in the present study reveal, this is subject to limitations. Nevertheless, this method can be used as a simple and rapid means of achieving direct species definition with the same protocol for both slow-growing species and fast-growing species.

Leite et $\mathrm{al}^{12}$ reported that PRA afforded rapid identification of species, but required a highly qualified staff and an adequately equipped laboratory for the achievement of good results. Those authors thus considered PRA to be more suitable for use in reference centers and in epidemiological research.

Despite the high cost necessary for accomplishment of the PRA technique employed in the present study, this method contributed to the rapid identification of mycobacteria at the species level, demonstrating that public health centers to which the population has easy access are potential sources of pathogenic mycobacteria. Considering that these places are visited mainly by immunodepressed patients, these subjects are at high risk of opportunistic infections, so the pathogenicity of NTM should not be overlooked.

By correlating the species identified by PRA in this study with pathogenicity, ${ }^{9}$ it can be seen that there is a slight prevalence of potentially pathogenic mycobacteria, which were found in larger amounts in the health center.

As for the distribution of potentially pathogenic species, namely $M$. malmoense type 1 and $M$. fortuitum type 1 , they were found in both institutions. The largest number of isolates of the former species was collected from the drinking fountain at the health center, followed by the floor and drains of washbasins in the bathrooms of the hospital wards. The 4 isolates that came from a drinking fountain is of particular concern, since it is a potential, easily accessible source of infection for anyone waiting to be attended and for the staff. In the case of immunodeficient patients, especially those carrying human immunodeficiency virus, Tortoli ${ }^{17}$ reported that infections caused by M. malmoense often disseminate throughout the body.

Two isolates of $M$. fortuitum type 1 came from toilet seats in the hospital wards. The fortuitum group of mycobacteria is responsible for most cases $(60 \%-80 \%)$ of postsurgical lesions and catheter infections. ${ }^{18}$ These facts are a cause for concern, since in the present survey $M$. fortuitum was recovered from the ward of a general hospital that offers all types of medical care and could thus represent a risk of hospital infection for immunodepressed inpatients using catheters. It is also worth noting that this species was isolated from a waiting room bench in the Lung Disease division of the health center, an unusual location among the chosen sampling points. This is a reminder that NTM (including potentially pathogenic mycobacteria) can be found on a wide range of surfaces in a health center.

All of the other potentially pathogenic mycobacteria were isolated in the health center: $M$. simiae type 4, M. lentiflavum types 1 and 3, M. kansasii type 4, M. genavense type 1, and M. avium type 2 .

All five isolates of $M$. simiae were found on the drinking fountain, which has already been mentioned as a source of more than one species of potentially pathogenic mycobacteria. It should be noted that exposure to $M$. simiae in the environment can be a risk factor for infection particularly in those who suffer from immunodeficiency, but it can also affect immunocompetent individuals. ${ }^{19,20}$

Two types of $M$. lentiflavum were found in three places in the health center, namely a tap in the common bathroom, the drain of the basin in the vaccine room, and the drinking fountain. This species has been identified as a cause of cervical lymphadenitis, lung diseases, and disseminated infections in AIDS patients. ${ }^{17}$

Another result worth highlighting is the fact that M. kansasii type 4, the species that furnished the largest 
number of isolates in the health center (12), was found only on the surface of the drinking fountain. This was, in fact, the sampling point where most of the potentially pathogenic ${ }^{9}$ species were concentrated and was by far the greatest reservoir of NTM. This observation deserves attention because a contaminated drinking fountain can be a ready source of infection; more effective disinfection procedures are needed in this area in order to eliminate these organisms from the health center. M. kansasii can cause lung diseases with clinical and radiological symptoms similar to $\mathrm{TB}$, which is associated with risk factors, such as bronchiectasis, chronic obstructive lung disease, TB sequelae, and immunosuppression. ${ }^{21}$ According to Chimara et al, ${ }^{22} M$. kansasii is the second most frequent cause of disseminated diseases in AIDS patients.

Just one specimen of $M$. avium type 2 (like $M$. fortuitum) was isolated from a bench in the health center waiting room. The environmental conditions on this surface are unsuitable for the growth of mycobacteria, so the presence of viable NTM proves that these microorganisms are capable of surviving in adverse conditions. ${ }^{5}$ Recently, researchers isolated $M$. avium complex (MAC) from the residential bathrooms of outpatients. MAC isolates were recovered from 15 out of the 29 bathrooms (52\%), including specimens from 14 bathtub inlets and 3 showerheads. Nearly half of these bathrooms (7/15) contained MAC strains that were identical or similar to their respective clinical isolates. These results indicate a risk of infection and/or reinfection for patients via use of bathtub and other sites in the bathroom. ${ }^{23}$

The species belonging to the MAC are considered to be some of the most important pathogens among NTMs. ${ }^{24}$ Apart from occasionally causing infections in immunocompetent patients, M. avium is one of the species that most frequently attacks AIDS patients, with the commonest manifestation in these cases being mycobacteremia. ${ }^{25}$

In conclusion, this study demonstrated that viable environmental mycobacteria were present in the public spaces within the health center and the hospital. These belonged to both potentially and rarely pathogenic species, and there was a higher incidence of the former in the health center.

This study also indicated that the PRA technique can be employed as a fast and easy method for the identification of environmental mycobacteria.

Such results reinforce the need for more effective disinfection at health centers, especially of the washbasins and drinking fountains, which can represent important sources of contamination. As there are no reports similar to our study, these data will add to the study of the epidemiology and control of these microorganisms.

\section{Disclosure}

The authors declare that there are no conflicts of interest.

\section{References}

1. Dubnau E, Chan J, Raynaud C, et al. Oxygenated mycolic acids are necessary for virulence of Mycobacterium tuberculosis in mice. Mol Microbiol. 2000;36:630-637.

2. Alcaide F, Richter I, Bernasconi C, et al. Heterogeneity and clonality among isolates of Mycobacterium kansasii: implications for epidemiological and pathogenicity studies. J Clin Microbiol. 1997;35:1959-1964.

3. British Thoracic Society. Management of opportunistic mycobacterial infections: Joint Tuberculosis Committee guidelines. Thorax. 2000;55:210-218.

4. Tortoli E. The new mycobacteria: an update. FEMS Immunol Med Microbiol. 2006;48:159-178.

5. Smeulders MJ, Keer J, Speight RA, Williams HD. Adaptation of Mycobacterium smegmatis to stationary phase. J Bacteriol. 1999;181:270-283.

6. Primm TP, Lucero CA, Falkinham JO. Health impacts of environmental mycobacteria. Clin Microbiol Rev. 2004;17:98-106.

7. Al-Mahruqi SH, van Ingen J, Al-Busaidy S, et al. Clinical relevance of nontuberculous mycobacteria, Oman. Emerg Infect Dis. 2009;15:292-294.

8. Narang R, Narang P, Mendiratta DK. Isolation and identification of nontuberculous mycobacteria from water and soil in central India. Indian J Med Microbiol. 2009;27:247-250.

9. Leão SC, Martin A, Mejia GL, et al. Practical Handbook for Phenotypic and Genotypic Identification of Mycobacteria. Brugge, Belgium: Vanden Broele; 2004.

10. Falkinham JO. Nontuberculous mycobacteria in the environmental. Clin Chest Med. 2002;23:529-551.

11. Telenti A, Marchesi F, Balz M, Bally F, Bottger EC, Bodmer T. Rapid identification of mycobacteria to the species level by polymerase chain reaction and restriction enzyme analysis. J Clin Microbiol. 1993;31:175-178.

12. Leite CQF, Rocha AS, Leite SRA, et al. A comparison of mycolic acid analysis for nontuberculous mycobacteria identification by thinlayer chromatography and molecular methods. Microbiol Immunol. 2005;49:517-578.

13. Kudoh S, Kudoh T. A simple technique for culturing tubercle bacilli. Bull World Health Organ. 1974;51:71-82.

14. Rocha AS, Werneck BAM, Dias CEC, et al. Novel allelic variants of mycobacteria isolated in Brazil as determined by PCR-restriction enzyme analysis of hsp65. J Clin Microbiol. 2002;40:4191-4196.

15. Falkinham JO. Epidemiology of infection by nontuberculous mycobacteria. Clin Microbiol Rev. 1996;9:177-215.

16. Bland CS, Ireland JM, Lozano E, Alvarez ME, Primm TP. Mycobacterial ecology of the Rio Grande. Appl Environ Microbiol. 2005;71:5719-5727.

17. Tortoli E. Impact of genotypic studies on Mycobacterium taxonomy: the new mycobacteria of the 1990s. Clin Microbiol Rev. 2003;16:319-354.

18. Brown-Elliott BA, Wallace RJJ. Clinical and taxonomic status of pathogenic nonpigmented or late-pigmenting rapidly growing mycobacteria. Clin Microbiol Rev. 2002;15:716-746.

19. Tsitko I, Rahkila R, Priha O, et al. Isolated and automated ribotyping for Mycobacterium lentiflavum from drinking water distribution system and clinical specimens. FEMS Microbiol Lett. 2006;256:236-243.

20. Gubler JGH, Salfinger M, von Graevenitz A. Pseudoepidemic of nontuberculous mycobacteria due to a contaminated bronchoscope cleaning machine. Chest. 1992;101:1245-1249.

21. Seiscento M, Bombarda S, Carvalho AC, Campos JRM, Teixeira L. Pleural effusion caused by nontuberculous mycobacteria. Braz J Pulmonol. 2005;31:459-463. 
22. Chimara E, Giampaglia CMS, Martins MC, Telles MAS, Ueki SYM, Ferrazoli L. Molecular characterization of Mycobacterium kansasii isolates in the state of São Paulo between 1995-1998. Mem Inst Oswaldo Cruz. 2004;99:739-743.

23. Nishiuchi Y, Tamaru A, Kitada S, et al. Mycobacterium avium complex organisms predominantly colonize in the bathtub inlets of patient's bathrooms. Jpn J Infect Dis. 2009;62:182-186.
24. Koh WJ, Kwon OJ, Lee KS. Nontuberculous mycobacterial pulmonary diseases in immunocompetent patients. Korean J Radiol. 2002;3:145-157.

25. Henry MT, Inamdar LOD, Schweiger M, Watson JP. Nontuberculous mycobacteria in non-HIV: epidemiology, treatment, and response. Eur Respir J. 2004;3:741-746.

\section{Publish your work in this journal}

Research and Reports in Tropical Medicine is an international, peerreviewed, open access journal publishing original research, case reports, editorials, reviews and commentaries on all areas of tropical medicine, including: Diseases and medicine in tropical regions; Entomology; Epidemiology; Health economics issues; Infectious disease; Laboratory science and new technology in tropical medicine; Parasitology; Public health medicine/health care policy in tropical regions; and Microbiology. The manuscript management system is completely online and includes a very quick and fair peer-review system. Visit http://www.dovepress. com/testimonials.php to read real quotes from published authors.

Submit your manuscript here: http://www.dovepress.com/research-and-reports-in-tropical-medicine-journal 